\title{
Exploring beliefs about dietary supplement use: focus group discussions with Dutch adults
}

\author{
Emília Margit Pajor*, Anke Oenema, Sander Matthijs Eggers and Hein de Vries \\ Department of Health Promotion, School of Public Health and Primary Care, Maastricht University, PO Box 616, \\ 6200 MD Maastricht, The Netherlands
}

Submitted 23 September 2016: Final revision received 22 May 2017: Accepted 16 June 2017: First published online 3 August 2017

\begin{abstract}
Objective: Although dietary supplement use is increasing in Europe and the USA, little research involving adults' beliefs regarding dietary supplements has been conducted. Therefore, the present study aimed to explore and compare users' and non-users' beliefs towards dietary supplements.

Design: Thirteen focus group discussions were conducted of which seven groups were dietary supplement users and six groups were non-users. Based on the socio-cognitive factors of the Integrated Change Model, a semi-structured topic guide was set up. The discussions were audio-recorded and subjected to qualitative content analysis, applying the framework approach.

Setting: Data were collected in Maastricht, the Netherlands, in 2014 and 2015.

Subjects: In total fifty-six individuals participated in the study, of whom twenty-eight were dietary supplement users and twenty-eight non-users. The average age of participants was 42.9 years.

Results: Dietary supplement users' attitude beliefs were mainly related to mental and physical health enhancement, illness prevention and curative health benefits. Users were critical of the nutritional knowledge of health professionals and of the quality of food products. Non-users were convinced that the human body does not need any support and that regular food is enough to cover one's nutritional needs. Users and non-users held comparable beliefs regarding the definition and risks of dietary supplements, and perceived social influences.

Conclusions: In their decision about dietary supplement use, both groups were guided by their own convictions to a great extent. Both groups would benefit from improved understanding of the health effects of dietary supplements to improve informed decision making.
\end{abstract}

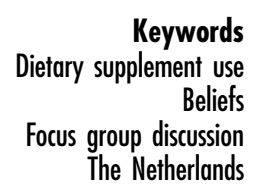

Dietary supplement use is increasing and widespread in many European countries and the USA ${ }^{(1,2)}$. As an example, $51.9 \%$ of the US adult population and $40 \%$ of the Dutch adult population takes dietary supplements regularly ${ }^{(3,4)}$. Yet evidence-based recommendations are established only for certain population subgroups ${ }^{(4-6)}$, such as vitamin D and calcium supplementation among the elderly, which lowers their risk of fractures ${ }^{(5)}$. There is no scientific consensus regarding the benefits of dietary supplement use at the general population level ${ }^{(7)}$. Therefore, it can be assumed that an individual's decision to take dietary supplements may be mainly a result of factors other than physiological necessity. Yet knowledge on individuals' motives for taking dietary supplements is fragmented and inconclusive. Furthermore, no research has yet addressed the question of why certain consumers consciously choose not to take them ${ }^{(8)}$. Therefore, the aim of the present study was to gather in-depth knowledge on individuals' beliefs concerning dietary supplements. In addition, users' and non-users' most salient beliefs would be compared.

Dietary supplement use has been shown to be associated with a healthy lifestyle: sufficient fruit and vegetable intake, adequate level of physical activity, low alcohol consumption and being less likely to smoke ${ }^{(9-11)}$. Additionally, women with a higher education level, higher income and belonging to higher age groups are more likely to take dietary supplements ${ }^{(11-13)}$.

Certain motivational factors are also associated with dietary supplement use. Women who have stronger intentions to take dietary supplements, attach more value to their health and are more convinced that dietary supplements make them less susceptible to illnesses, are significantly more inclined to take dietary supplements ${ }^{(14)}$. Regarding one's reasons for and beliefs towards dietary supplement use, 
individuals are convinced that dietary supplements are essential to health and can preserve or improve their overall health condition ${ }^{(1,8,13,15-17)}$. When comparing dietary supplement users with non-users, the following attitude beliefs differ significantly: dietary supplements 'help me to be healthy'; 'stop me getting ill'; 'are the best I can do for myself; and 'don't do any harm, ${ }^{,(18)}$. The studies mentioned above provided relevant but limited evidence since data were collected within the framework of larger projects, such as the National Health and Nutrition Examination Survey ${ }^{(1)}$, or the study used a selective sample ${ }^{(14,18)}$.

Qualitative research on beliefs regarding dietary supplement use is limited to a couple of studies that did not use a specific theoretical framework. In-depth interviews with ten dietary supplement users revealed that curing an ailment, preventing chronic diseases, gaining 'peace of mind', supplementing a poor diet, saving money on medical care and achieving cosmetic benefits are the most salient motives ${ }^{(8)}$. Taking an anthropological approach, Nichter and Thompson ${ }^{(17)}$ identified the following five main categories of reasons for dietary supplement use: health management/enhancement (e.g. postponing ageing); harm reduction (e.g. counterbalance unhealthy behaviours); resisting illness (e.g. boost immune system); illness management (e.g. slow progress of disease); and ideology (e.g. adoption of 'natural health' philosophy). Four focus group discussions held in Germany revealed the following motives among users: being afraid of having micronutrient deficiencies; relieving one's mind (unhealthy eating habits); preventive reasons (boost immune system); curative reasons (reduce health complaints); and restoring subjective well-being (e.g. sufficient energy level ${ }^{(19)}$. Studies have also shown that most dietary supplement users have multiple reasons at the same time ${ }^{(8,17)}$.

The studies mentioned above explored users' overall motives for taking dietary supplements, but no attention has been paid to why certain individuals do not use dietary supplements. To explore specific beliefs and to be able to compare users and non-users, a socio-cognitive model was used as the theoretical framework in the present study. One of the socio-cognitive theories that explains (health) behaviours is the Integrated Change Model (ICM) ${ }^{(20)}$. The ICM distinguishes between distal, pre-motivational and motivational factors that may influence behaviour. Distal factors, such as behavioural, psychological and biological factors, have an indirect effect on behaviour that is mediated by pre-motivational and motivational factors. Knowledge, risk perception, awareness and cues to action belong to premotivational factors. These socio-cognitive determinants further influence motivational factors: attitude (pros and cons), social influence (social norm, social modelling, social support) and self-efficacy. Intentions and factors of the motivational phase together influence individuals' health behaviour. The ICM has been applied previously in different qualitative studies on health-related behaviours, such as alcohol use among pregnant women, binge drinking among young people, and genetics and cancer ${ }^{(21-23)}$.

In sum, the present study aimed to answer the following research questions: (i) What are the most salient beliefs derived from the socio-cognitive determinants of the ICM regarding dietary supplements among users and non-users? (ii) What are the differences between users' and non-users' beliefs?

\section{Methods}

To gather in-depth information on Dutch individuals' beliefs towards dietary supplements, semi-structured focus group discussions were conducted. Focus group discussion is a widely used method in health sciences, since it can provide information about a range of ideas and feelings individuals have about a certain topic of interest $^{(24,25)}$. Furthermore, focus group discussions can shed light on the differences in perspectives between groups of individuals ${ }^{(25)}$. The in-depth information generated was also meant as a preparation for a quantitative study on dietary supplement use. Systematic interpretative content analysis was used as the methodological approach of analysing the data ${ }^{(26)}$.

\section{Recruitment and participants}

The aim was to include both current dietary supplement users and non-users in the study sample. To make a distinction between users and non-users, inclusion and exclusion criteria were set up. Individuals were regarded as dietary supplement users if they took at least one pill per week of one or more types of dietary supplements prior to the recruitment period of the study. Individuals who consumed dietary supplements exclusively for sports-related purposes were excluded. Athletes' needs, reasons and experiences regarding dietary supplement use may be mostly related to enhancing their sporting achievements, which may not be representative of the general population of dietary supplement users ${ }^{(19)}$. The only inclusion criterion applied for non-users was not having taken any type of dietary supplements for three months prior to the recruitment period.

Online and offline platforms were utilized for recruitment. Digital advertisements were posted on social media and Internet search engines, such as Google AdWords. Hard copies of brochures and posters were placed on the noticeboards of grocery shops, drugstores, community centres and general practices in Maastricht. Researchers recruited also through the handing out of flyers at local events, such as the Maastricht book fair.

Individuals who were interested in the study could contact the research team by telephone or email to receive more information about it. When potential participants applied, they were asked to fill in a brief screening questionnaire to assess eligibility. Based on the answers, participants were 
allocated either to the dietary supplement user group or to the non-user group. Focus group appointments were made according to respondents' availability.

Convenience sampling was used for recruiting participants until theoretical saturation (e.g. little or no new information was discovered) was reached ${ }^{(27)}$. As suggested by Krueger and Casey ${ }^{(28)}$, an initial analysis sample was set to at least four to five focus groups in order to adequately address the research objective (i.e. to explore the most prevalent beliefs) ${ }^{(29)}$. Additionally, after each session the research team discussed the main points participants made and to what extent those points differed from opinions expressed in previous sessions. Recruitment took place as long as potential participants kept replying to the call for participation.

\section{Focus group interview guide}

Based on the $\mathrm{ICM}^{(23)}$, a semi-structured interview guide with open-ended questions was developed. The questions aimed to elicit data on participants' definition of what a dietary supplement is, risk perception, attitudes (pros and cons), social environment (i.e. opinion of friends and family), self-efficacy of taking dietary supplements and response efficacy. Each topic was introduced by a central question, followed by additional prompt questions to stimulate the group discussion (see online supplementary material, Supplemental Tables 1 and 2). The semi-structured interview guide also gave individuals the opportunity to talk about additional relevant topics, such as (healthy) food.

The interview questions were pilot-tested both in an individual and a group setting. With the help of pilot-testing, researchers can develop and test the adequacy of research instruments $^{(30)}$. Questions used for focus groups of users and non-users were as similar as possible, with slight changes made where needed (e.g. advantages of dietary supplements, users: 'What are your most important reasons for taking dietary supplements?'; non-users: 'Can you think of reasons why you would take dietary supplements?').

\section{Data collection and procedure}

A standardized study protocol was established to keep the procedures of each session consistent. According to the protocol, after welcoming participants and providing coffee, tea and cake, a short introduction (research team, reason and aims of the study) was given. As stated in the invitation letter beforehand, it was emphasized that taking part in the discussion was confidential and voluntary and that withdrawal from participation was possible at any time. Participants were asked to write down their first name on a name badge to enable them to address each other by name. At the same time, individuals received a numerical identifier that was used in the notes and the transcripts. In this manner, it was impossible to trace back participants' real identity based on the data. Before the actual discussion started, participants had the opportunity to ask questions. The focus group discussions were audio-recorded after participants gave permission to do so.
During the focus group discussions, the first author (E.M.P.) functioned as moderator and a research assistant took notes. The sessions took place in one of the buildings of Maastricht University and lasted 70 to $80 \mathrm{~min}$ on average. At the end of the sessions participants received vouchers to the value of $15 €$ and a travel reimbursement. The focus group audio materials were transcribed verbatim. In total thirteen focus group interviews were conducted; seven with dietary supplement users (twentyeight individuals) and six with non-users (twenty-eight individuals). The focus group size varied between three and six participants.

\section{Ethics approval}

Ethics approval from an accredited Regional Medical Ethics Committee in the Netherlands was not needed, since the study does not fall within the scope of the Medical Research Involving Human Subjects Act (WMO): the present research is not of medical-scientific nature and participants were not subjected to procedures or required to follow certain rules of behaviour (http://www.ccmo.nl/ en/your-research-does-it-fall-under-the-wmo). Prior to the focus group discussions, all participants received our brochure and invitation letter with important details about the study. This information was repeated verbally in the presence of participants before the actual group discussion took place. Verbal informed consent was obtained from all participants before each session.

\section{Data analysis}

Descriptive statistics (i.e. percentages, frequencies) were used to analyse the data of the screening questionnaire with the statistical software package IBM SPSS Statistics version 20. Transcripts of the focus group discussions were analysed by applying systematic interpretative content analysis ${ }^{(26)}$, using the qualitative data analysis software QSR NVivo version 9. The analysis process followed the stages of the framework approach involving familiarization, identifying a thematic framework, indexing, charting, mapping and interpretation ${ }^{(31,32)}$.

In the first stages, inductive coding was applied to the data independently by two coders. This step involved obtaining insight into participants' salient beliefs belonging to the socio-cognitive constructs included in the topic guide (main themes). Coding was then compared and discussed to determine the final coding categories for users' and non-users' transcripts separately. Also, decision rules were made to standardize the coding process in the subsequent stages.

In the last stages, through deductive coding, the definite version of the thematic framework was applied to the data by two coders, using NVivo version 9 (2010). This step involved regrouping participants' statements according to the index reference and, if needed, new coding categories were established ${ }^{(31)}$. 


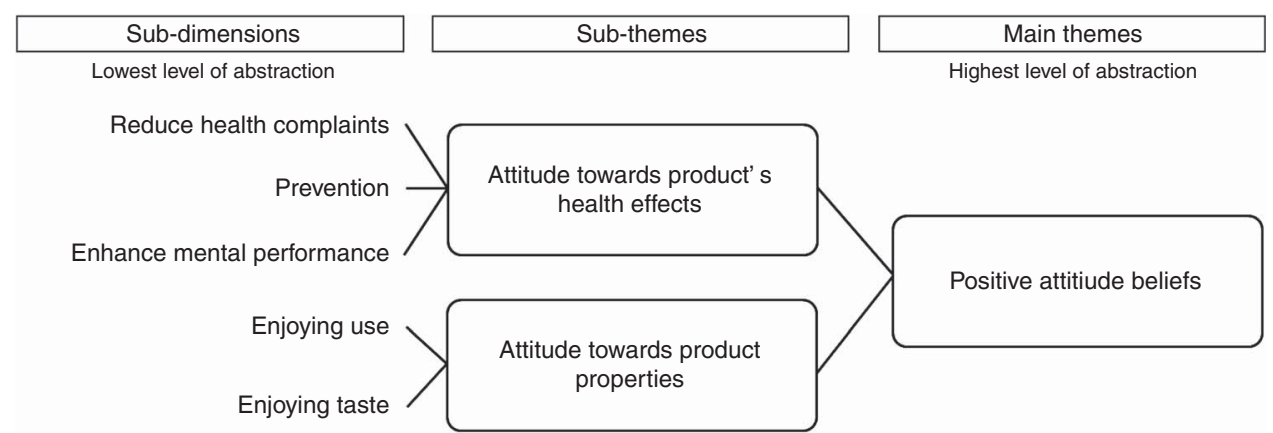

Fig. 1 An example of the abstraction process (positive attitude beliefs, users)

In the interpretation phase data were reduced to present results at a reasonable level of abstraction. Through grouping data, the number of (coding) categories was reduced by collapsing those that were closely related into broader categories $^{(33)}$. In this manner, the most concrete and specific beliefs were at the lowest level of abstraction, and were then brought under integrative categories (sub-themes). At the highest level of abstraction are socio-cognitive constructs which are regarded as the main themes and consist of several sub-themes (Fig. 1). During data interpretation, users' and non-users' complete thematic frameworks were put against one another and were searched for differences and similarities at the sub-dimension level.

\section{Results}

\section{Participants}

In total, fifty-six individuals participated in the study. The majority were female ( $75 \%$ of users; $61 \%$ of non-users). Users were slightly younger (mean age 41.6 years, range 20-78 years) than non-users (mean age 44.2 years, range 19-68 years). More than the half of non-users (57.1\%) had past experience with using dietary supplements (see Table 1).

\section{A priori and emergent themes from the qualitative data}

The following themes were a priori included in the topic guide: (i) definition of what is a dietary supplement; (ii) positive attitude beliefs towards dietary supplements (advantages, reasons for use); (iii) negative attitude beliefs towards dietary supplements (disadvantages, reasons against use); (iv) risk perception (chance and severity of adverse effects); (v) social environment; (vi) self-efficacy regarding taking dietary supplements; and (vii) response efficacy (noticing product efficacy). Emerging themes from the focus group discussions were: (viii) attitude towards health professional and/or dietitian; and (ix) quality/safety of food, practices of food industry. In Tables 2, 3 and 4 direct quotations are given for illustrating each of these topics. Results are presented according to the overarching topics outlined above.
Table 1 Demographic characteristics of participants $(n 56)$ in focus group discussions on dietary supplement use, Maastricht, the Netherlands, 2014-2015

\begin{tabular}{|c|c|c|c|c|}
\hline \multirow[b]{2}{*}{ Characteristic } & \multicolumn{2}{|c|}{$\begin{array}{l}\text { Users } \\
(n 28)\end{array}$} & \multicolumn{2}{|c|}{$\begin{array}{l}\text { Non-users } \\
\quad(n \text { 28) }\end{array}$} \\
\hline & $n$ & $\%$ & $n$ & $\%$ \\
\hline \multicolumn{5}{|l|}{ Gender } \\
\hline Male & 7 & $25 \cdot 0$ & 11 & 39.0 \\
\hline Female & 21 & $75 \cdot 0$ & 17 & 61.0 \\
\hline \multicolumn{5}{|l|}{ Age (years) } \\
\hline $18-29$ & 13 & 46.4 & 10 & 35.7 \\
\hline 30-39 & 3 & $10 \cdot 7$ & 0 & 0.0 \\
\hline $40-49$ & 3 & $10 \cdot 7$ & 4 & $14 \cdot 3$ \\
\hline 50-59 & 3 & $10 \cdot 7$ & 9 & $32 \cdot 1$ \\
\hline$\geq 60$ & & $25 \cdot 0$ & 5 & 17.9 \\
\hline Mean age (years) & \multicolumn{2}{|c|}{41.6} & \multicolumn{2}{|c|}{44.2} \\
\hline \multicolumn{5}{|c|}{ Past experience of dietary supplements } \\
\hline Former user & NA & NA & 16 & $57 \cdot 1$ \\
\hline No experience at all & NA & NA & 12 & $42 \cdot 9$ \\
\hline
\end{tabular}

NA, not applicable.

\section{A priori themes}

\section{Pre-motivational factors}

Definition of dietary supplements. Users and non-users held very similar opinions about what a dietary supplement is and what its main functions are (Table 2, row A-B). Dietary supplements were described along several product property dimensions, such as their aggregate (e.g. liquid), form (e.g. powders, pills, drops), and type and nature of ingredients (e.g. vitamins, minerals, synthetic, natural).

Regarding functions that dietary supplements could fulfil, both users and non-users agreed that dietary supplements are by no means a replacement for food, and they should not be used out of pure laziness. The way dietary supplements may help to maintain health and treat micronutrient deficiencies in one's body was also extensively discussed across several groups of users and non-users.

Risk perception. When speaking about commonly used products (e.g. multivitamins) risks were regarded as negligible by both groups (Table 2, row C-D) and participants gave a few examples of possible side-effects (Table 2, row E). Users and non-users were convinced that most dietary supplements may only cause adverse effects 


\begin{tabular}{|c|c|c|}
\hline Main theme & Sub-theme & Quotes from dietary supplement users \\
\hline \multicolumn{3}{|c|}{ DEFINITION OF DIETARY SUPPLEMENTS } \\
\hline A & $\begin{array}{l}\text { Characteristics of the } \\
\text { product }\end{array}$ & $\begin{array}{l}\text { 'It [dietary supplement] is something that you can find in food, but its } \\
\text { [dietary supplement] concentration is higher.' }\end{array}$ \\
\hline \multirow[t]{4}{*}{ B } & $\begin{array}{l}\text { Functions of the product/ } \\
\text { purposes of use }\end{array}$ & $\begin{array}{l}\text { Supplementary function towards food: 'A dietary supplement } \\
\text { alone is never enough. (...) It [dietary supplements] must have an } \\
\text { additional value [to the diet].' }\end{array}$ \\
\hline & & $\begin{array}{l}\text { Function towards body: '(...) it [dietary supplement] is something } \\
\text { that makes good a [possible] shortage in your body.' }\end{array}$ \\
\hline & & $\begin{array}{l}\text { Ease: 'I do not eat fruit and it is also very expensive. I live on my own } \\
\text { and when I buy bananas, it takes a while until I finish them. Then I } \\
\text { think to myself: "perhaps I should take such a pill".' }\end{array}$ \\
\hline & & $\begin{array}{l}\text { Alternative for medicine: 'Sometimes you have to take medicines, } \\
\text { but you do not want to. Then you do a search in natural medicine: } \\
\text { what could replace it [medicine]? Very often you end up [the } \\
\text { search] at dietary supplements.' }\end{array}$ \\
\hline \multicolumn{3}{|c|}{ RISK PERCEPTION } \\
\hline C & Chance and severity & $\begin{array}{l}\text { Low risk: 'Most of the things I have been using have become very } \\
\text { well established, like multivitamins. So you already know it does } \\
\text { not hurt to try.' } \\
\text { High risk: '(...) when you are using St. John's Wort with } \\
\text { antidepressants simultaneously, you may die of it.' }\end{array}$ \\
\hline \multirow[t]{2}{*}{$\mathrm{D}$} & Deteriorating factors & $\begin{array}{l}\text { Excessive use: '(...) Sometimes people take not only one, but two or } \\
\text { three [pills] of [dietary supplement]. (...) It is equal to } 600 \text { oranges. } \\
\text { (...) It is actually hypervitaminosis.' } \\
\text { Malfunctioning/sensitivity of the body: 'It depends on your own } \\
\text { sensitivity. Everybody has strong and weak points, right?' }\end{array}$ \\
\hline & & $\begin{array}{l}\text { Characteristics of the product: 'You have to pay attention to what } \\
\text { you take, because there are so many chemicals in it [dietary } \\
\text { supplements]. (...) Everybody takes the cheapest [dietary } \\
\text { supplement], (...) but they never look at what is in it.' }\end{array}$ \\
\hline$E$ & Possible side-effects & $\begin{array}{l}\text { 'Iron pills, they may colour your defecation black. You may have } \\
\text { problems with your bowel.' }\end{array}$ \\
\hline $\mathrm{F}$ & Safety check/protection & $\begin{array}{l}\text { 'I do not think they [possible side-effects] are serious. The dose is } \\
\text { stated [on the packaging] with small letters. If it was really harmful, } \\
\text { it would not be sold unrestricted, or it [dose] would be stated with } \\
\text { bigger letters.' } \\
\text { 'I do not think about it. It must be good. Otherwise it would be } \\
\text { prohibited to sell them. They [government] are already strict.' }\end{array}$ \\
\hline
\end{tabular}

Quotes from non-users of dietary supplements

[Dietary supplements are] everything you may need in a pill format or other formats like drops (...), or capsules (...), and they are often produced in a synthetic manner.'

Supplementary function towards food: 'The word [dietary supplement] itself already tells you: it is supplementary. So, what you perhaps or definitely don't get enough of [from food], you could supplement with dietary supplements.'

Function towards body: 'Possibly in periods when you suffer from shortcomings. When you have a lack of energy. You may need it owing to doing sports (...) or after being ill for a while.

Ease and certainty: '(...) people who are aware of their bad dietary pattern might say: "well, with the use of multivitamins I cover my needs, so I know for sure that I'm getting enough [of (micro) nutrients]".'

Alternative for medicine: "I would not immediately take a pill prescribed by the doctor, I would first try a different pill that I can buy myself, you know.'

Low risk: 'Most of the vitamins cannot do any harm, even if you took too many of them because they will leave your body in your urine.

High risk: 'Vitamin $B_{6}$ is a type of vitamin that might become toxic and may attack your nerves.

Excessive use: 'Vitamin A may have [adverse effects]. You should not take that much of it. It is not good for your liver. It may be stored excessively. And then you are getting a high dose.

Malfunctioning/sensitivity of the body: 'It [risks] depends on your own body. (...) If you already have poor health then I think you may notice the consequences of an overdose sooner.'

notice the consequences of an overdose sooner.'
Characteristics of the product: 'When I was using dietary

Characteristics of the product: 'When I was using dietary
supplements, it was stated on the label that you get $600 \%$ of the RDA [with the use of that dietary supplement]. Then I was just wondering: "600\% (...) is it necessary?" You may get an overdose.

I know with iron pills that you may get a lot of troubles with them. You might get stomach-ache or diarrhoea from them. And your stools may be a different colour.

'No, you do not get side-effects easily when you take a low dose [of dietary supplements], otherwise you should get it [prescribed] from a general practitioner'

prohibited to sell them. They [government] are already strict. 
Table 3 Qualitative results from focus group discussions regarding motivational factors among users and non-users of dietary supplements, Maastricht, the Netherlands, 2014-2015

\begin{tabular}{|c|c|c|c|}
\hline Main themes & Sub-theme & Quotes from dietary supplement users & Quotes from non-users of dietary supplements \\
\hline \multicolumn{4}{|c|}{ POSITIVE ATTITUDE BELIEFS } \\
\hline \multirow[t]{3}{*}{ A } & \multirow[t]{3}{*}{$\begin{array}{l}\text { Attitude towards } \\
\text { product's effects on } \\
\text { one's body and mind }\end{array}$} & $\begin{array}{l}\text { Reduce health complaints: 'I suffer from pain in my shoulders. (...) } \\
\text { I hope that it [dietary supplement] will make the situation better (...). } \\
\text { It seems I have arthrosis.' }\end{array}$ & $\begin{array}{l}\text { Reduce health complaints: 'People, who are more sickly or weak, or } \\
\text { unsure. Those people (...) take dietary supplements very quickly.' }\end{array}$ \\
\hline & & $\begin{array}{l}\text { Prevention: 'I think you get a stronger immune system with the use of } \\
\text { vitamin C and echinacea.' }\end{array}$ & $\begin{array}{l}\text { Prevention: 'Well, I think that for example people usually start using it for } \\
\text { preventing illnesses.' }\end{array}$ \\
\hline & & $\begin{array}{l}\text { Enhance mental performance: 'Most products I use are meant for } \\
\text { mental well-being, an example is ginseng. It is meant for enhancing } \\
\text { my study performance.' }\end{array}$ & $\begin{array}{l}\text { Being at risk of deficiency: '(...) people who suffer from anaemia need } \\
\text { vitamin } B_{12} \text { injections every month. Otherwise you have a deficiency of } \\
\text { red blood cells.' }\end{array}$ \\
\hline B & $\begin{array}{l}\text { Attitude towards the use } \\
\text { of the product or the } \\
\text { product itself }\end{array}$ & $\begin{array}{l}\text { Enjoying use: 'I like to use this product. It is royal jelly. It is very delightful } \\
\text { when I am weak and I don't feel well.' } \\
\text { Enjoying taste: '(...) my mother had a very big jar of vitamin C tablets. } \\
\text { I was eating it all the time because they tasted so good.' }\end{array}$ & $\begin{array}{l}\text { Effectiveness is evidence-based: 'The reason why I would actually use } \\
\text { it [dietary supplement] is that its effectiveness has been confirmed.' } \\
\text { Control with pills on health: 'It is a typical sign of an affluent society. } \\
\text { I mean the idea that people are able to influence their health with pills } \\
\text { or dietary supplements.' }\end{array}$ \\
\hline $\mathrm{C}$ & Influence of commercials & NA & $\begin{array}{l}\text { 'In my opinion, it is more the commercial that wants to convince you to take } \\
\text { something than that you are in such a need of it [dietary supplements].' }\end{array}$ \\
\hline $\mathrm{D}$ & Ease & NA & $\begin{array}{l}\text { 'Sometimes the idea occurs to me that people just find it easier because } \\
\text { they are not fond of something and so they take a pill.' }\end{array}$ \\
\hline \multicolumn{4}{|c|}{ NEGATIVE ATTITUDE BELIEFS } \\
\hline E & $\begin{array}{l}\text { Product properties and } \\
\text { sales-related } \\
\text { disadvantages }\end{array}$ & $\begin{array}{l}\text { 'Lately I bought a jar of "Guarana } 800 \mathrm{mg} \text { - it is quite a high dosage, } \\
\text { so I may get hyper[active] from it.' } \\
\text { Commercialization: 'There are some brands and it is like a "hype" with lots } \\
\text { of advertisements, commercials and marketing.' }\end{array}$ & $\begin{array}{l}\text { 'In my opinion, it is a kind of synthetic version of it [vitamin C], because it } \\
\text { cannot be literally the same thing as what is in an orange.' } \\
\text { Commercialization: 'There is actually a whole industry by which enormous } \\
\text { amounts of money can be earned.' }\end{array}$ \\
\hline $\mathrm{F}$ & $\begin{array}{l}\text { Consumers' health, } \\
\text { functioning and } \\
\text { lifestyle-related } \\
\text { disadvantages }\end{array}$ & $\begin{array}{l}\text { Hinder healthy eating: 'I may easily assume that I eat healthily when I take } \\
\text { multivitamins. So it may be an excuse for eating less vegetables and fruits.' } \\
\text { Not natural: 'I am using them [dietary supplements]. But you feel like you are } \\
\text { doing something unnatural. So you don't let things stand at: "a varied diet is } \\
\text { enough".. }\end{array}$ & $\begin{array}{l}\text { Hinder healthy eating: 'When you are using dietary supplements, I think } \\
\text { you are more inclined to leave fruits and vegetables.' } \\
\text { Normal way of functioning: 'I consider it important that my body nourishes } \\
\text { itself, I do not want my body to get habituated [to dietary supplements].' }\end{array}$ \\
\hline G & (No) necessity & $\begin{array}{l}\text { Conscious use: 'You should only take something when you need it. It is } \\
\text { beneficial to investigate critically and experience [the product]. You may } \\
\text { leave it [dietary supplements] for a while or try out something new, when it } \\
\text { is necessary.' }\end{array}$ & $\begin{array}{l}\text { Need: 'In my opinion you should only use a dietary supplement - which is } \\
\text { meant for deficiency - when it is needed.' } \\
\text { Healthy diet is enough: 'I think you should eat healthily and varied, this is } \\
\text { the best [for yourself] I think. Things like this [dietary supplements] are } \\
\text { only needed in exceptional cases.' }\end{array}$ \\
\hline $\mathrm{H}$ & $\begin{array}{l}\text { Safety check/ } \\
\text { investigation }\end{array}$ & $\begin{array}{l}\text { 'Some possible side-effects have not been properly investigated yet and may } \\
\text { become clearer only in the future.' }\end{array}$ & $\begin{array}{l}\text { '(...) it is very often claimed that it [dietary supplement] may not be harmful. } \\
\text { But it still has not been fully investigated.' }\end{array}$ \\
\hline 1 & $\begin{array}{l}\text { Lack of (evidence-based) } \\
\text { effects }\end{array}$ & $\begin{array}{l}\text { 'Maybe the [beneficial] effect is not evidence-based.' } \\
\text { 'Look, some people do not digest vitamin } B_{12} \text {. So you can take whatever you } \\
\text { want but it won't have an effect.' }\end{array}$ & $\begin{array}{l}\text { 'Does it [dietary supplement] contain what it should contain? And does it } \\
\text { work when you take it? You never know.' }\end{array}$ \\
\hline \multicolumn{4}{|c|}{ SOCIAL ENVIRONMENT } \\
\hline \multirow[t]{2}{*}{$\mathrm{J}$} & \multirow[t]{2}{*}{ Positive opinion } & $\begin{array}{l}\text { '(...) my mother says that you can always use something on the side [besides } \\
\text { food]. Therefore I take vitamin C (...), but I have never really had any } \\
\text { [physical] complaints.' }\end{array}$ & $\begin{array}{l}\text { "When I arrived at home and I told I was tired, my parents gave me an iron } \\
\text { pill. "Try this, it may help you"." }\end{array}$ \\
\hline & & $\begin{array}{l}\text { Using dietary supplements: 'Well, I think my girlfriend, my parents and my } \\
\text { sister are taking dietary supplements. And some fanatical friends of mine } \\
\text { from the gym [are also taking dietary supplements].' }\end{array}$ & $\begin{array}{l}\text { Using dietary supplements: 'Yes, friends of mine (...) who feel weak and } \\
\text { have to get out of their bed, then they take vitamin pills or energy } \\
\text { boosters.' }\end{array}$ \\
\hline $\mathrm{K}$ & $\begin{array}{l}\text { Dietary supplements are } \\
\text { harmless }\end{array}$ & 'It [taking dietary supplements] does not hurt to try.' & 'It [taking dietary supplements] does not hurt to try - they say.' \\
\hline L & Negative opinion & $\begin{array}{l}\text { 'At the college where I study "dietary supplement" is almost a nasty word. } \\
\text { They are really against it [dietary supplements]' }\end{array}$ & $\begin{array}{l}\text { 'When you do not have any symptoms (...) most people think then: "What is } \\
\text { the benefit of it [dietary supplements]?"' }\end{array}$ \\
\hline M & (Healthy) food is enough & $\begin{array}{l}\text { '(...) my friends are saying all the time: if you simply eat healthily, then they } \\
\text { [(micro)nutrients] are all included in it [food]. Then you do not need to take } \\
\text { something additionally.' }\end{array}$ & $\begin{array}{l}\text { 'I have got four sisters and none of them takes them [dietary supplements]. } \\
\text { One says: "I wouldn't even start using them [dietary supplements] } \\
\text { because I eat healthily".' }\end{array}$ \\
\hline
\end{tabular}




\begin{tabular}{|c|c|c|c|}
\hline Main themes & Sub-theme & Quotes from dietary supplement users & Quotes from non-users of dietary supplements \\
\hline $\mathrm{N}$ & No idea & 'My environment does not say anything about it [dietary supplements].' & $\begin{array}{l}\text { 'I have to admit, it is not a topic that is frequently discussed. I have never } \\
\text { talked about it.' }\end{array}$ \\
\hline \multicolumn{4}{|c|}{ SELF-EFFICACY } \\
\hline O & $\begin{array}{l}\text { Difficult situations (to } \\
\text { quitting dietary } \\
\text { supplement use) }\end{array}$ & $\begin{array}{l}\text { Medical reason: 'For me, it [taking dietary supplements] is for medical } \\
\text { reasons because my body does not digest everything. So I have to play } \\
\text { around with those dietary supplements all the time because otherwise I do } \\
\text { not get anything [(micro)nutrients].' } \\
\text { Risk of deficiency: 'When you know or feel that your body is not functioning } \\
\text { as it should or your body has a deficiency. Then not to take [dietary } \\
\text { supplements] would feel like (...) you are wronging yourself or your body.' }\end{array}$ & $\begin{array}{l}\text { Medical reason: '(...) indeed, if you have a certain disorder or Crohn's } \\
\text { disease. Or your body is not able to digest nutrients from your intestine. } \\
\text { When people have chemotherapy treatment, and do not eat properly. } \\
\text { Also you do not feel well so in that case you could use something extra.' } \\
\text { Risk of deficiency: 'I am a vegetarian. So you can easily sustain deficiency } \\
\text { of iron or vitamin } B_{12 .} \text {. (...) I can imagine that people think "it is weird not } \\
\text { to eat meat" and they are afraid that they do not get enough vitamins. So I } \\
\text { can imagine that they would take particular vitamins as a } \\
\text { supplementation.' }\end{array}$ \\
\hline $\mathrm{P}$ & $\begin{array}{l}\text { Difficult situations (to } \\
\text { taking dietary } \\
\text { supplements) }\end{array}$ & $\begin{array}{l}\text { External barrier: 'Yes, exactly, being on holiday. (...) It is difficult when you } \\
\text { are somewhere else and you don't take them with you, then you cannot } \\
\text { take them.' } \\
\text { Internal barrier: 'You should not forget to take them [dietary supplements]. I notice } \\
\text { immediately when I have forgotten to take them. So my tactic is to put them } \\
\text { somewhere so I do not forget them [dietary supplements]. }\end{array}$ & $\begin{array}{l}\text { External barrier: 'I am not really good at swallowing pills. I had to swallow } \\
\text { the [vitamin] pills whole and those were for really big pills. They also } \\
\text { tasted very bad, so it did not make it easy to get them down.' }\end{array}$ \\
\hline \multicolumn{4}{|c|}{ RESPONSE EFFICACY } \\
\hline Q & $\begin{array}{l}\text { Effect of product is } \\
\text { present/noticeable }\end{array}$ & $\begin{array}{l}\text { '(...) when I was diagnosed with arthrosis I was not able to do certain things. } \\
\text { For example, when I got on my bike and had to give the first push, it hurt } \\
\text { me. (...) After using this substance for three months, it [pain] has gone } \\
\text { away.' }\end{array}$ & NA \\
\hline W & $\begin{array}{l}\text { Effect of product is } \\
\text { absent/unnoticeable }\end{array}$ & $\begin{array}{l}\text { 'My [vitamin] } B_{12} \text { level was considerably lower than the lower boundary of } \\
\text { [vitamin] } B_{12} \text { (..) I took vitamin } B_{12}, \text { I took a vitamin } B \text { complex product. I } \\
\text { have been checked several times for vitamin } B_{12} \text {. But taking the pill } \\
\text { [vitamin } B \text { complex] had no effect or result.' }\end{array}$ & NA \\
\hline z & $\begin{array}{l}\text { Doubt/uncertainty about } \\
\text { effectiveness or } \\
\text { noticing effects }\end{array}$ & $\begin{array}{l}\text { Placebo effect: 'But even if it is a placebo effect, it doesn't matter. Of course it's } \\
\text { not worth the money. But when it [dietary supplement] has a placebo effect and } \\
\text { I am able to walk again from here, then I am fine with it.' } \\
\text { Effect is difficult to determine/measure: 'I have tried a lot of things to get } \\
\text { rid of my energy shortage. I also did something with aloe vera so I cannot } \\
\text { indicate it [what helped] precisely because I did not use them consecutively } \\
\text { but simultaneously.' } \\
\text { Prevention: 'If you use them [dietary supplements] for preventive purposes } \\
\text { then you do not know. You do not know whether you otherwise had noticed } \\
\text { something [symptoms] or got an illness. (...) You may prevent something, } \\
\text { but you don't know.' }\end{array}$ & NA \\
\hline
\end{tabular}

NA, not applicable.

Words in capitals are the main themes of the group discussions. A-Z are sub-themes of the main themes. Words in bold font are dimensions of the sub-themes. 
Table 4 Qualitative results from focus group discussions' newly identified themes among users and non-users of dietary supplements, Maastricht, the Netherlands, 2014-2015

\begin{tabular}{|c|c|c|}
\hline Main themes & Sub-theme & Quotes from dietary supplement users \\
\hline \multicolumn{3}{|c|}{ ATTITUDE TOWARDS HEALTH PROFESSIONAL AND/OR DIETITIAN } \\
\hline A & Positive attitude, trust & $\begin{array}{l}\text { 'I trust my general practitioner and also the dietitian, but I am a very } \\
\text { critical person.' }\end{array}$ \\
\hline B & $\begin{array}{l}\text { Negative attitude, } \\
\text { distrust }\end{array}$ & $\begin{array}{l}\text { 'Very often it [advice on diet] is done at a general level (...). The } \\
\text { person [dietitian] keeps giving the same advice while perhaps } \\
\text { someone is sitting in front of you who perhaps needs something } \\
\text { totally different. (...) I know more about it [diet] than the person on } \\
\text { the opposite side of the table. And that person suggests things, } \\
\text { which [food pyramid] are old old-fashioned.' } \\
\text { 'I never consult with a dietitian. I would have an argument with them } \\
\text { immediately. Simply because, generally speaking, I do not agree } \\
\text { with their recommendations.' }\end{array}$ \\
\hline
\end{tabular}

QUALITY/SAFETY OF FOOD, PRACTICES OF FOOD INDUSTRY

Positive attitude

NA

D Negative attitude
Quotes from non-users of dietary supplements

When I do not feel well I am more inclined to go to a [health] professional like "I do not feel well (...) how come?" And then

you can decide to take something against it [illness].'

Better supply: 'Nowadays, if you look around you see how many cherry tomatoes or mini-cucumbers or salads people eat in the afternoon. In my opinion, you have more opportunities to eat healthily than about 50 years ago when the supply was more restricted. Then you had only vegetables of the actual season:

I think that the supply of food, including industrial food, is quite good and it is rich enough in minerals, and is very low in harmful substances on the surface.'

Quality of food is good enough: 'I think too that in certain cases it could be that it is less [micronutrients in food], but you have to ask yourself: is the amount that much less (...) that I get nothing or not enough [of micronutrients from food]?

Poor quality of food: 'It is awful what they sell in supermarkets. For example, spinach is full of some kind of substance to let it grow better. I do not eat spinach anymore because it is such a mess.' 'If you make a comparison between now and 100 years ago ... for example in our spinach - there are less nutrients than 100 years ago. Poor practices of food industry: 'I think the ground can become depleted. If the ground is depleted, then you get fewer minerals from it [ground].

NA, not applicable.

Words in capitals are the main themes of the group discussions. A-D are sub-themes of the main themes. Words in bold font are dimensions of the sub-themes. 
when they are excessively used, when the consumer's body is not functioning properly, or when someone is using inappropriate products (Table 2, row D). Users and non-users also believed that dietary supplements undergo rigorous safety checks before being sold, otherwise - they argued it would not be permitted to sell those products (Table 2, row F).

\section{Motivational factors}

Positive attitude beliefs. Regarding reasons for dietary supplement use, reducing health complaints and preventing illnesses were frequently mentioned aspects both by users and non-users (Table 3, row A). Users also reported how dietary supplements help them enhance their mental performance. Also, users indicated enjoying the taste and use of dietary supplements (Table 3, row B).

Only non-users discussed micronutrient deficiency and evidence-based effectiveness of the products as important reasons for considering taking dietary supplements (Table 3, row B). In addition, only non-users indicated that, in general, the persuasiveness of commercials or individuals' laziness could also lead to dietary supplement use (Table 3, row $\mathrm{C}-\mathrm{D})$.

Negative attitude beliefs. Both users and non-users regarded the commercial nature of the dietary supplement industry as a disadvantage (Table 3, row E). Also, in both groups concerns were expressed towards product properties, such as high-dosage pills, uncertainty about ingredients and lack of sufficient evidence of safety (Table 3, row E-I). Regarding eating habits, users and non-users agreed that individuals' nutritional intake may decline as a consequence of using dietary supplements (Table 3, row F).

While users raised the issue that getting micronutrients from dietary supplements is not natural, non-users went further and regarded dietary supplements as an intervention in the normal functioning of the body (Table 3, row F). Concerning necessity (Table 3, row G), users emphasized the need to think thoroughly about the aims one will achieve with dietary supplements and then decide whether to (continue) to take them. Non-users approached necessity differently: supplementation is only necessary when suffering from deficiencies and there is no need for dietary supplements if individuals already eat healthily (Table 3, row G).

In several groups of users an extensively discussed topic was whether micronutrients from dietary supplements are properly absorbed through the digestive system (Table 3, row I).

Social environment. Both users and non-users reported being exposed to different social influences at the same time. Individuals in their social environment held different opinions about dietary supplement use, ranging from being positive and encouraging to being negative and discouraging (Table 3, row $\mathrm{J}-\mathrm{N}$ ). Besides approvers and disapprovers, there were also people in participants' social environment who consider regular food as a sufficient source of nutrients and therefore taking dietary supplements is not necessary (Table 3, row M). Furthermore, users and non-users often heard from others that dietary supplements are harmless (Table 3, row K).

Both users and non-users indicated that their decision regarding dietary supplement use did not depend on others' opinions. At the same time, both groups admitted that 'dietary supplement use' is not a commonly talked about topic.

Self-efficacy. Users and non-users mentioned situations in which dietary supplement use would be difficult (Table 3, row P). Some of the situations mentioned by both groups were: having a different (daily) routine than usual (e.g. being on holiday) or not liking the taste of the product. Users also frequently mentioned forgetfulness as a barrier to taking dietary supplements.

Additionally, users and non-users mentioned a few situations in which they would never stop using dietary supplements: when suffering from micronutrient deficiencies and in the case of medical prescription (Table 3, row O).

Response efficacy. Only users were asked whether they actually experience the beneficial health effects that dietary supplements are intended for (Table 3, row Q-Z). Users agreed that taking dietary supplements can help people improve their health. Yet users' opinions differed regarding their ability to experience directly those beneficial health effects. Only some of them could precisely indicate whether and how they notice the advantageous effects, and a large number of participants gave a detailed explanation as to why they have doubts about an immediate experience (Table 3, row W-Z). Users' doubts were related to the preventive use of the products and the difficulty in determining effectiveness. Furthermore, users were aware of possible placebo effects through which dietary supplements may seem to be effective.

\section{Emergent themes}

Attitude towards bealth professional and/or dietitian One of the unprompted discussion topics raised both by users and non-users was their experience with and opinion towards physicians (Table 4 , row A-B). Several users had had unfavourable experiences with their physician, such as not being able to diagnose a health problem. Users also did not confide in dietitians and labelled their recommendations as 'old-fashioned' or 'inappropriate'. However, several users consulted regularly with so-called anthroposophical general practitioners (adherents of a spiritual philosophy aiming to optimize physical and mental health, and well-being) who gave them advice about lifestyle and diet, including recommendations for dietary supplements. In contrast, the majority of non-users held a positive attitude towards their physician (Table 4 , row A). 
Quality/safety of food, practices of food industry

An additional frequently discussed topic by users and nonusers was food quality (Table 4, row C-D). Very often, a comparison was made between food nowadays and 50-100 years ago regarding quality, supply and food industry practices. The majority of users were convinced that the quality of food products has gone downhill recently and food contains considerably lower amounts of vitamins and minerals (Table 4, row D). As users further argued, quality deterioration is a result of poor practices by the food industry.

Non-users acknowledged that the quality of food products may have declined a little recently. Yet food products still may contain sufficient amounts of vitamins, minerals and other important nutrients. Moreover, compared with 100 years ago, there is more opportunity to eat healthily as a result of the enriched variety of supply of fruits and vegetables (Table 4, row C).

\section{Discussion}

The present study sought to explore and compare users' and non-users' salient beliefs related to dietary supplement use, applying the ICM as its theoretical background. Users' and non-users' beliefs were comparable regarding the risks of dietary supplements, how they define dietary supplements, and their decision regarding whether or not to take dietary supplements being independent from their social environment. Users' and non-users' beliefs differed substantially regarding their attitude beliefs towards dietary supplements, trust in health professionals and judgement on the quality of food products.

The majority of users and non-users defined dietary supplements as products that are intended to supplement the normal diet. Both groups considered the risks of dietary supplements as low and assigned the occurrence of possible adverse effects more to the consumer (e.g. excessive use, being ill) than to the product. How dietary supplements are judged by significant others (e.g. family, friends) did not seem to influence participants' own decision about whether to use dietary supplements or not.

Users considered dietary supplements as a potential tool to improve their health. Users' most frequently mentioned reasons for taking dietary supplements can be grouped into three overarching categories: preventive reasons (e.g. to avert getting the flu); mental and physical health enhancement (e.g. to enhance mental performance); and curative benefits (e.g. to reduce health complaints). Users' motivations were most commonly related to certain (health) complaints that they suffered from. This finding is in line with previous research that suggests that health problems such as joint pain, muscle cramp, osteoporosis or arthritis are frequently mentioned motives for taking dietary supplements, especially among the elderly ${ }^{(1,34)}$.
In contrast, non-users put emphasis on investigating the necessity of use first when discussing reasons for taking dietary supplements. As they argued, nutritional deficiencies can be detected, for example with the help of a blood test. Non-users indicated that a healthy, balanced and varied diet would be of sufficient quality for most people to cover their nutritional needs. Additionally, most non-users were convinced that the human body is able to regulate all the different biological processes properly on its own. Therefore, they considered supporting the normal functioning of the body with dietary supplements as unnecessary. Hence, non-users did not feel the need to improve their health as much as users did.

Most dietary supplement users were critical of general practitioners' and dietitians' knowledge on nutrition, whereas the majority of non-users did not have such a critical view of their physician. Research has shown that $44 \%$ of frequent dietary supplement users believed that their own physician knows little to nothing about nutrition $^{(13)}$. The distrust towards health-care providers was also revealed by previous research showing that dietary supplement users often took control of their own health by seeking alternative forms of medicine, including dietary supplements $^{(10)}$.

Users' and non-users' beliefs regarding food quality and safety also differed considerably. Whereas users estimated food quality as poor, non-users still considered food products as a sufficient source of nutrients. Evidence suggests that dietary supplement users tend to have a healthy lifestyle and sufficient nutritional intake ${ }^{(11,12,35)}$. The fact that dietary supplement users feel the need to supplement their nutritious diet might be explained by their distrust in food quality.

It is important to note that many users were uncertain whether they actually experienced any of the advantageous health effects of dietary supplements. Despite these doubts, users still believed that dietary supplements help improve their health. High levels of response efficacy may explain a contradictory result of a previous study: about $70 \%$ of dietary supplement users would still take dietary supplements, even if the government or the Food and Drug Administration announced that dietary supplements are ineffective ${ }^{(13)}$.

The findings mentioned above may imply that both users and non-users base their decision regarding dietary supplement use mainly on their beliefs. To facilitate consumers' informed decision-making regarding dietary supplement use, users' and non-users' understanding of dietary supplements' health effects should be improved.

\section{Limitations}

As with many qualitative studies, the present sample may be biased since convenience sampling was used to recruit participants. Therefore, future research should assess individuals' motives towards dietary supplement use quantitatively, using a representative sample. The semi-structured topic guide made it possible to standardize the study procedure 
and topics discussed. But due to the predefined nature of the discussions, participants had limited opportunities to discuss relevant topics that were not included in the topic guide. With regard to theoretical saturation, the research team evaluated each session in terms of differences and similarities in beliefs compared with previous sessions, but some aspects of dietary supplement use may be still undiscovered. As an example, in contrast to previous studies, compensation for unhealthy eating habits was not raised as a reason for taking dietary supplements by users ${ }^{(17,19)}$.

\section{Implications for future research}

Data were collected among a selective sample of Dutch individuals in the region of Maastricht. Therefore, the study should be extended to more areas in the Netherlands as well as to other countries.

Several salient beliefs regarding dietary supplements, food and health have been discovered in the present study. However, it is impossible to investigate the predictive value of those beliefs regarding dietary supplement use based on qualitative research. Therefore, future quantitative longitudinal studies should assess to what extent socio-cognitive factors determine dietary supplement use and non-use, and address the question of, for example, whether decreased trust in physicians and negative judgement on food quality may indeed lead to dietary supplement use.

Some salient beliefs identified by the current study can be related to existing theoretical constructs, such as mental and physical health enhancement and illness prevention, which correspond to the two motivational needs distinguished by the regulatory focus theory ${ }^{(36)}$. In addition, the differing needs of users and non-users for managing their own health can be related to Rotter's locus of control theory ${ }^{(37)}$. Therefore, the predictive value of relevant socio-cognitive and psychosocial factors of such theories should be tested statistically in a representative sample of the Dutch population.

\section{Conclusion}

The aim of the present study was to explore and compare dietary supplement users' and non-users' beliefs towards dietary supplement use through applying the ICM as its theoretical background. Users' and non-users' beliefs corresponded to a large extent regarding their definition of dietary supplements, the evaluation of the risks of dietary supplements and the influence of the social environment. Users' and non-users' beliefs differed considerably regarding their attitude beliefs towards dietary supplements, their trust in health professionals and their trust in the quality of food products.

\section{Acknowledgements}

Acknowledgements: The authors would like to thank the participants for sharing their opinions on dietary supplement use, and the research assistants who performed different tasks. Financial support: This study was funded by the Netherlands Food and Consumer Safety Authority. The Netherlands Food and Consumer Safety Authority had no role in the design, analysis or writing of this article. Conflict of interest: The authors have no conflict of interest to declare. Authorship: Each author of this article contributed significantly to the study. All authors read and approved the final manuscript. Ethics of buman subject participation: Ethics approval from an accredited Regional Medical Ethics Committee in the Netherlands was not needed, since the study does not fall within the scope of the Medical Research Involving Human Subjects Act (WMO): the present research is not of medical-scientific nature and participants were not subjected to procedures or required to follow certain rules of behaviour (http://www.ccmo.nl/en/your-research-does-itfall-under-the-wmo). Prior to the focus group discussions, all participants received our brochure and invitation letter with important details about the study. This information was repeated verbally in the presence of participants before the actual group discussion took place. Verbal informed consent was obtained from all participants.

\section{Supplementary material}

To view supplementary material for this article, please visit https://doi.org/10.1017/S1368980017001707

\section{References}

1. Bailey RL, Gahche JJ, Thomas PR et al. (2013) Why US children use dietary supplements. Pediatr Res 74, 737-741.

2. Skeie G, Braaten T, Hjartåker A et al. (2009) Use of dietary supplements in the European Prospective Investigation into Cancer and Nutrition calibration study. Eur J Clin Nutr $\mathbf{6 3}$, Suppl. 4, S226-S238.

3. Briefel RR \& Johnson CL (2004) Secular trends in dietary intake in the United States. Annu Rev Nutr 24, 401-431.

4. Van Rossum C, Fransen H, Verkaik-Kloosterman J et al. (2011) Dutch National Food Consumption Survey 20072010: Diet of Children and Adults Aged 7 to 69 Years. RIVM report no. 350050006/2011. Bilthoven: National Institute for Public Health and the Environment; available at http:// www.rivm.nl/bibliotheek/rapporten/350050006.pdf

5. Health Council of the Netherlands (2015) Dutch Dietary Guidelines 2015. Advisory Report no. 2015/26E. The Hague: Health Council of the Netherlands; available at https://www. gezondheidsraad.nl/sites/default/files/201524edutch_dietary_ guidelines_2015.pdf

6. US Department of Health and Human Services, National Institutes of Health (2015) Multivitamin/mineral supplements. https://ods.od.nih.gov/factsheets/MVMS-HealthProfessional/ (accessed May 2015).

7. Harrison R, Holt D, Pattison D et al. (2004) Are those in need taking dietary supplements? A survey of 21923 adults. Br J Nutr 91, 617-623.

8. Okleshen Peters CL, Shelton J \& Sharma P (2004) An investigation of factors that influence the consumption of dietary supplements. Health Mark $Q$ 21, 113-135.

9. De Jong N, Ocke MC, Branderhorst HA et al. (2003) Demographic and lifestyle characteristics of functional food consumers and dietary supplement users. Br J Nutr 89, 273-281. 
10. Greger JL (2001) Dietary supplement use: consumer characteristics and interests. J Nutr 131, 4 Suppl., 1339S-1343S.

11. Kirk SF, Cade JE, Barrett JH et al. (1999) Diet and lifestyle characteristics associated with dietary supplement use in women. Public Health Nutr 2, 69-73.

12. Bailey RL, Gahche JJ, Lentino CV et al. (2011) Dietary supplement use in the United States, 2003-2006. J Nutr 141, 261-266.

13. Blendon RJ, DesRoches CM, Benson JM et al. (2001) Americans' views on the use and regulation of dietary supplements. Arch Intern Med 161, 805-810.

14. Conner M, Kirk SF, Cade JE et al. (2001) Why do women use dietary supplements? The use of the theory of planned behaviour to explore beliefs about their use. Soc Sci Med 52, 621-633.

15. Marinac JS, Buchinger CL, Godfrey LA et al. (2007) Herbal products and dietary supplements: a survey of use, attitudes, and knowledge among older adults. J Am Osteopath Assoc 107, 13-23.

16. Rozga MR, Stern JS, Stanhope K et al. (2013) Dietary supplement users vary in attitudes and sources of dietary supplement information in East and West geographic regions: a cross-sectional study. BMC Complement Altern Med 13, 1.

17. Nichter M \& Thompson JJ (2006) For my wellness, not just my illness: North Americans' use of dietary supplements. Cult Med Psychiatry 30, 175-222.

18. Conner M, Kirk SF, Cade JE et al. (2003) Environmental influences: factors influencing a woman's decision to use dietary supplements. J Nutr 133, issue 6, 1978S-1982S.

19. Rehaag R, Tils G, Röder B et al. (2013) Zielgruppengerechte Risikokommunikation zum Thema Nabrungsergänzungsmittel. Abschlussbericht. Berlin: Bundesinstitut für Risikobewertung; available at http://www.bfr.bund.de/cm/350/zielgruppenger echte-risikokommunikation-zum-thema-nahrungsergaenzungs mittel.pdf

20. De Vries H, Mudde A, Leijs I et al. (2003) The European Smoking prevention Framework Approach (EFSA): an example of integral prevention. Health Educ Res 18, 611-626.

21. van der Wulp NY, Hoving C \& de Vries H (2013) A qualitative investigation of alcohol use advice during pregnancy: experiences of Dutch midwives, pregnant women and their partners. Midwifery 29, e89-e98.

22. Jander A, Mercken L, Crutzen R \& de Vries H (2013) Determinants of binge drinking in a permissive environment: focus group interviews with Dutch adolescents and parents. BMC Public Health 13, 1.

23. de Vries H, Mesters I, Van de Steeg H et al. (2005) The general public's information needs and perceptions regarding hereditary cancer: an application of the Integrated Change Model. Patient Educ Couns 56, 154-165.

24. Stewart DW \& Shamdasani PN (2014) Focus Groups: Theory and Practice. London: SAGE Publications Ltd.

25. Rabiee F (2004) Focus-group interview and data analysis. Proc Nutr Soc 63, 655-560.

26. Hijmans E (1996) The logic of qualitative media content analysis: a typology. Communications 21, 93-108.

27. Glaser BG \& Strauss AL (2009) The Discovery of Grounded Theory: Strategies for Qualitative Research. London: Transaction Publishers.

28. Krueger RA \& Casey MA (2014) Focus Groups: A Practical Guide for Applied Research. London: SAGE Publications Ltd.

29. Francis JJ, Johnston M, Robertson C et al. (2010) What is an adequate sample size? Operationalising data saturation for theory-based interview studies. Psychol Health 25, 1229-1245.

30. Van Teijlingen E \& Hundley V (2002) The importance of pilot studies. Nurs Stand 16, 33-36.

31. Ritchie J \& Spencer L (2002) Qualitative data analysis for applied policy research. Qual Res Comp 573, 305-329.

32. Lacey A \& Luff D (2009) Qualitative Data Analysis. Nottingham/Sheffield: The National Institute for Health Research (NIHR) Research Design Service for the East Midlands/The NIHR Research Design Service for Yorkshire \& the Humber; available at https://www.rds-yh.nihr.ac.uk/ wp-content/uploads/2013/05/9_Qualitative_Data_Analysis_ Revision_2009.pdf

33. Elo S \& Kyngäs H (2008) The qualitative content analysis process. J Adv Nurs 62, 107-115.

34. Brownie S \& Rolfe M (2005) Supplement utilisation patterns of older Australians: results from a randomly selected national sample. Nutr Diet 62, 89-94.

35. Bailey RL, Fulgoni VL, Keast DR et al. (2011) Dietary supplement use is associated with higher intakes of minerals from food sources. Am J Clin Nutr 94, 1376-1381.

36. Higgins ET (2002) How self-regulation creates distinct values: The case of promotion and prevention decision making. J Consum Psychol 12, 177-191.

37. Rotter JB (1966) Generalized expectancies for internal versus external control of reinforcement. Psychol Monogr 80, 1-28. 